NBER WORKING PAPER SERIES

\title{
HEDONIC PRICE INDEXES FOR PERSONAL COMPUTER OPERATING SYSTEMS AND PRODUCTIVITY SUITES
}

\author{
Alan G. White \\ Jaison R. Abel \\ Ernst R. Berndt \\ Cory W. Monroe \\ Working Paper 10427 \\ http://www.nber.org/papers/w10427
NATIONAL BUREAU OF ECONOMIC RESEARCH
1050 Massachusetts Avenue
Cambridge, MA 02138
April 2004

This research was originally sponsored by Microsoft Corporation in the context of various antitrust allegations, and was conducted under the direction of Ernst Berndt. The opinions expressed herein are those of the authors and not necessarily those of Microsoft Corporation, its legal counsel, MIT, or the NBER. The authors gratefully acknowledge the assistance and input of many on this project - in particular, Sarita Digumarti and Eric Korman for careful and thorough research assistance, other staff at Analysis Group, and Microsoft counsel for helpful comments and suggestions. The views expressed herein are those of the author(s) and not necessarily those of the National Bureau of Economic Research.

(C)2004 by Alan G. White, Jaison R. Abel, Ernst R. Berndt, and Cory W. Monroe. All rights reserved. Short sections of text, not to exceed two paragraphs, may be quoted without explicit permission provided that full credit, including (C) notice, is given to the source. 
Hedonic Prices Indexes for Personal Computer Operating Systems and Productivity Suites Alan G. White, Jaison R. Abel, Ernst R. Berndt, and Cory W. Monroe

NBER Working Paper No. 10427

April 2004

JEL No. D4, E3, L86

\title{
ABSTRACT
}

Results of hedonic price regressions for personal computer operating systems and productivity suites advertised in PC World magazine by retail vendors during the time period 1984 to 2000 are reported. Among the quality attribute variables we use are new measures capturing the presence of network effects in personal computer operating systems, such as connectivity and compatibility, and product integration among components of productivity suites. Average annual growth rates of qualityadjusted prices of personal computer operating systems range from -15 to -18 percent, while those for productivity suites generally range between -13 and -16 percent. Price declines are generally greater in the latter half of the samples.

\author{
Alan G. White \\ Analysis Group \\ Boston, MA \\ awhite@analysisgroup.com \\ Jaison R. Abel \\ Analysis Group \\ Boston, MA \\ jabel@analysisgroup.com \\ Ernst R. Berndt \\ Sloan School of Management \\ MIT, E52-452 \\ 50 Memorial Drive \\ Cambridge, MA 02142 \\ and NBER \\ eberndt@mit.edu \\ Cory W. Monroe \\ Sloan School of Management \\ MIT \\ cwmonroe@sloan.mit.edu
}




\section{Introduction}

The introduction of the IBM personal computer in 1981 marked the beginning of a revolution in information technology that has continued to present day. ${ }^{1}$ The IBM PC set the standard for personal computing, and with its wide appeal, helped produce a new industry that would change forever the way in which people would live and work. Powered by an Intel 8088 microprocessor and Microsoft's PC DOS 1.0 operating system, users of the IBM PC at that time could create modest documents, make basic spreadsheets, and play simple games. Through time, rapid technological advances in computer hardware have lead to the development of new and improved software that have allowed users to accomplish significantly more with their personal computer.

While a significant amount of research has been conducted examining the qualityadjusted prices of personal computer hardware, ${ }^{2}$ a surprisingly small amount of research has focused on measuring such prices for software. In addition, the research that does exist on this topic has focused exclusively on stand-alone applications, such as spreadsheets and word processors. ${ }^{3}$ Since the mid-1990s, however, stand-alone applications have increasingly been sold as components of integrated productivity suites. ${ }^{4}$ Hence the relevance of this previous research to contemporary product forms is unclear. Moreover, the existing hedonic price index literature has ignored personal computer operating systems all together. In this paper, we seek to fill this void in the existing literature by reporting on research estimating quality-adjusted measures of price change for prepackaged personal computer operating systems and productivity suites over the time period 1984 to 2000 . To the best of our knowledge, this research represents the first hedonic pricing analysis for personal computer operating systems and productivity suites.

Using price quotes collected from monthly issues of PC World magazine for the years 1984 through 2000, along with information on product attributes drawn from a variety of sources

\footnotetext{
1 The Altair 8800, which was introduced by MITS in 1975, is generally regarded as the world's first "personal computer." However, this product was generally purchased by hobbyists and kit makers, rather than the every day consumer. The IBM PC, on the other hand, was the first personal computer to gain mass appeal.

2 See, for example, Lynch, Rao, and Lin [1990], Berndt [1991] ch. 4, Berndt and Griliches [1993], Rao and Lynch [1993], Berndt, Griliches, and Rappaport [1995], Berndt and Rappaport [2001, 2002], and Pakes [2003]. Gandal's [1994] study of prepackaged spreadsheet software is the first known hedonic analysis of personal computer software.

$4 \quad$ See, for example, the discussion in Abel, Berndt, and White [2003].
} 
on personal computer operating systems and productivity suites, we estimate parameters in hedonic regression equations that measure price changes adjusted for the impact of quality variation. Among the quality attribute measures we develop are ones capturing connectivity and compatibility for operating systems and product integration for productivity suites. We construct such measures to account for the important phenomena of network effects and product integration in the market for prepackaged software. ${ }^{5}$ In this respect, our study also contributes to the small but growing literature seeking to empirically identify and measure the presence of network effects in information technology markets.

A limitation of our research is that it focuses on sales of prepackaged personal computer software sold through retail outlets. While the previous literature has also focused on this distribution channel, sales of software through the retail channel of distribution have become increasingly unrepresentative of prepackaged software transactions. ${ }^{6}$ Instead, today's software transactions are now most commonly through large-account distributors or bundled with personal computer hardware sold by original equipment manufacturers (“OEMs”) such as Compaq, Dell, and Gateway.

Our principal conclusion is that the quality-adjusted prices of personal computer operating systems and productivity suites have declined substantially over time. While we investigate a number of alternative model specifications, our results are remarkably robust. The prices of operating systems have declined at average annual growth rates ("AAGRs") ranging approximately from 15 to 18 percent over the period 1987 to 2000, with slightly lower declines between 1987 to 1993 compared to 1993 to 2000. For productivity suites, over the longer period from 1984 to 2000, AAGRs are generally between -13 to -16 percent, with prices falling more rapidly in the 1992 to 2000 time period compared to 1984 to 1992 . Matched-model price indexes in most, but not all cases, reveal considerably slower rates of price decline than we find for hedonic quality-adjusted price indexes. We make a number of observations concerning the differences in estimated rates of price decline based on hedonic compared to matched-model

A network effect exists when the value of a product increases with the number of users of compatible products. Network effects have previously been examined in the context of prepackaged software by Gandal [1994, 1995] through the inclusion of product compatibility measures and by Brynjolfsson and Kemerer [1996] by including measures of a product's installed base in their hedonic regressions.

6 See Abel, Berndt, and White [2003] for a complete discussion of this issue for Microsoft's prepackaged software. 
methods, and also comment on recent literature that proposes an alternative price index measurement methodology.

\section{Background on Hedonic Quality-adjustment Techniques}

The literature and research on hedonic quality-adjustment techniques is extensive and spans a number of decades. Early studies of quality-adjustment techniques can be found in Waugh [1928] (for asparagus, hothouse tomatoes, and cucumbers) and Court [1939] (for automobiles). Zvi Griliches' seminal work in 1961 is widely recognized as having formed much of the modern basis of hedonic price analysis, based on the application of multivariate regression techniques to adjust price indexes for quality change over time. ${ }^{7}$

The importance of the need to adjust price measures for quality change continues to be a topic of current interest. Given the dynamic nature of certain sectors within the economy and the continual introduction of a range of new products each year with improved quality, the need for measures of quality-adjusted price changes has become ever more important. In addition to the much-publicized Boskin Commission Report of 1996 that estimated the extent of upward-biased growth in the U.S. Consumer Price Index (“CPI”), detailed studies have also been conducted by The Conference Board [1999] and the National Academy of Sciences [2002]. In addition, the U.S. Bureau of Labor Statistics ("BLS") is continuing to sponsor in-house and external research focusing on estimating hedonic price indexes for various components of the consumer and producer price indexes ("PPI"), including, among others, personal computers, DVD players, camcorders, refrigerators, and microwave ovens.

Among issues prominent in the recent literature on hedonic price indexes are the presence and interpretation of temporal instability in estimated coefficients of hedonic price equations (e.g., Berndt, Griliches, and Rappaport [1995], Berndt and Rappaport [2001, 2002], Aizcorbe [2003a, b], Heravi and Silver [2002]; Pakes [2003], and Triplett [2003], chs. 3 and 5); factors affecting differences between price indexes computed using matched-model compared to hedonic regression methods (e.g., Aizcorbe [2003b, c], Aizcorbe, Corrado, and Doms [2003], Heravi and Silver [2002], and Triplett [2003] ch. 5); choice of functional form (e.g., Berndt and

A useful recent discussion of econometric estimation issues in hedonic regressions in general, and with a specific application to personal computer hardware, is that by Pakes [2003]. 
Rappaport [2002], Diewert [2003], Feenstra [1995], Pakes [2003] and Triplett [2003], ch. 5); and the use of fixed-effects econometric specifications instead of explicit product characteristics measures as regressors in hedonic price equations (e.g., Aizcorbe, Corrado, and Doms [2003]). We address the implications of our analyses for some of this literature later in the paper.

\section{Existing Research on Prepackaged Software Price Measurement}

Before proceeding with a discussion of our implementation of hedonic price estimation for personal computer operating systems and productivity suites, we first briefly review the existing research on price measurement for prepackaged software. Table 1 summarizes the main findings of the studies of which we are aware. This research shows that prepackaged software prices have generally been declining over time, although rates of price decline in some cases differ considerably across products and time periods.

\section{Consumer Price Indexes}

Relatively few published papers report measures of quality-adjusted price changes for prepackaged software over time. An early effort by Oliner and Sichel [1994] employs matchedmodel price index methods to control for quality change over time by intertemporally comparing prices for only similar software products. Using price quotes collected from various personal computer magazines for the period 1985 to 1993, they find AAGR declines in prepackaged software prices of 2.6, 4.5, and 4.7 percent for word processors, spreadsheets, and databases, respectively. Estimates of quality-adjusted price declines for the U.S. prepackaged software market using hedonic regression techniques are reported in Gandal [1994, 1995], Brynjolfsson and Kemerer [1996], and McCahill [1997]. Over the 1986 to 1991 time period, Gandal [1994] finds declines in hedonic quality-adjusted prices for spreadsheets of 15 percent per annum, ${ }^{8}$ generally consistent with the final declines reported by Brynjolfsson and Kemerer [1996] that lie in the range of 14.8 to 16.5 percent per annum covering 1987 to 1992, and by McCahill [1997] in the range of 9.0 to 16.9 percent per annum for the period 1986 to $1993 .{ }^{9}$ McCahill [1997] also

\footnotetext{
8 Gandal [1995] also finds declines in quality-adjusted prices for spreadsheets of 4.4 percent per annum over the shorter time period 1989 to 1991 .

Earlier estimates by Brynjolfsson and Kemerer, cited by Oliner and Sichel, reported considerably smaller rates of price decline.
} 
reports declines in quality-adjusted prices for word processors in the range of 15.1 to 18.5 percent annually, while Gandal [1995] reports a smaller decline of 1.5 percent annually for databases over the period 1989 to 1991. Finally, using an alternative quality-adjustment methodology, based on counts of function points, McKinsey Global Institute [2001] reports a price decline of 11.7 percent for Microsoft's operating systems from 1988 to 1998.

The number of non-U.S. studies is even smaller. Grohn [n.d.] reports hedonic estimates of declines in quality-adjusted price indexes for word processors in the range of 11.3 to 36.9 percent per annum for Germany over the 1985 to 1995 time period. Harhoff and Moch [1997] also analyze prepackaged software price trends in Germany from 1986 to 1994. Based on price quotes from German personal computer magazines, they compare price trend results using both matched-model and hedonic price index methods. Interestingly, they report a decline in their price index for databases of 9.25 percent per annum using matched-model methods, a greater rate of price decline than that found based on hedonic methods (7.41 percent). Harhoff and Moch attribute this finding to the fact that older versions of database software were sold at greatly reduced retail prices as newer versions were introduced to the market.

The only other non-U.S. study of software price change of which we are aware is that by Prud'homme and $\mathrm{Yu}$ [2002] for Canada, based on Nielsen scanner data. They report price declines for an aggregate of all prepackaged software in the range of 4.4 to 7.9 percent per annum using matched-model price indexes for the period 1996 to 2000, and for a substantial number of sub-aggregates covering a wide range of prepackaged software products, including games. Two prominent findings in Prud'homme and $\mathrm{Yu}$ are that rates of price decline differ considerably across various types of prepackaged software (high for games, smaller for operating systems), and that because of rapidly changing market shares, growth rates of price indexes differ substantially (even, in some cases, in sign) depending on whether one uses base-period Laspeyres weights or current-period Paasche weights.

It is worth noting that these findings are limited in scope and relevance for the majority of software sales today, for several reasons. First, with the exception of Prud'homme and Yu [2002], the studies referenced in Table 1 report results that employ data ending in the early to mid-1990s. Second, these studies of software price measurement have focused almost exclusively on retail or mail order transactions. As noted in Abel, Berndt, and White [2003], for a software company like Microsoft, sales of full-packaged products sold through the retail 
channel have become an ever smaller and unrepresentative portion of sales over time, with volume-related sales constituting a greater percentage of software application sales. Moreover, OEM sales such as those to Compaq and Dell are not tracked by these studies, which instead tend to focus on the final software consumer. Although some of these transactions are better captured by a producer rather than a consumer price index, the fact remains that much prepackaged software is sold in bundled form with hardware, most likely at implicit prices quite different from retail shrink-wrapped prepackaged software. Third, the existing literature has focused on measuring price trends for applications sold as stand-alone products, which have increasingly been replaced by productivity suites. A final limitation of some of these studies is their use of list price measures in computing a consumer price index. Most studies (notably, Gandal [1994, 1995], Brynjolfsson and Kemerer [1996], and McCahill [1997]) focus on the list price (such as the suggested retail price reported by National Software Testing Laboratories) when computing a consumer price index, in contrast to the more appropriate transactions price as in Prud'homme and Yu [2002]. The prices used in our study are collected from advertisements, which we believe closely approximate transactions prices.

\section{Producer Price Indexes}

Abel, Berndt, and White [2003] compute price indexes for products sold by Microsoft at the first line of distribution. To the best of our knowledge, this is the only published producer price index for software, other than that published by the BLS. Price index calculations are based on the universe of Microsoft's sales in the U.S. at the first line of distribution, and encompass sales both to the finished goods (i.e., distributors and resellers) and OEM channels of distribution. Full versions, upgrades, and volume-licensing sales are also incorporated into the analyses. Using a Fisher matched-model price index, Abel, Berndt, and White report average annual declines in prices from 1993 to 2001 for Office (4.78 percent), Word (10.64 percent), Excel (8.17 percent), and personal computer operating systems (0.39 percent). Price indexes are also computed treating the Office suite as a product distinct from its stand-alone Word and Excel components, and by combining stand-alone and productivity suite sales for Word and for Excel.

\section{Official Government Price Indexes}

As part of its expanded producer price index coverage, the BLS first began publishing a monthly producer price index for prepackaged software in December 1997. The BLS 
prepackaged software price index is based on a survey of producer selling prices, i.e., at the first line of distribution, collected from a sample of manufacturers of prepackaged software. The BLS collects price quotes from both the OEM and finished goods channels, for full versions and upgrades. To preserve continuity in the index, the BLS attempts to collect price quotes for comparable products over time. The current methodology of the index is a fixed basket matched-model Laspeyres price index with plans to update the company-specific index weights every five to seven years. ${ }^{10}$ Over the period December 1997 to December 2003, the BLS PPI for prepackaged software declined at an annual rate of 1.06 percent. In comparison, over the same time period the BLS CPI for prepackaged software declined at an annual rate of 8.51 percent. ${ }^{11}$

The Bureau of Economic Analysis ("BEA") also computes a software price index for purposes of reporting quarterly measures of U.S. real gross domestic product and real gross domestic product by industry. The BEA software price index draws on research from a number of the prepackaged software studies listed in Table 1. As noted by Grimm and Parker [2000], with respect to the hedonic price index studies for prepackaged software, the existing literature reveals that hedonic quality-adjusted prices for spreadsheets and word processors have generally fallen more rapidly than have corresponding matched-model price indexes. ${ }^{12}$ This occurs since matched-model methods typically fail to capture fully many quality improvements between different versions and generations of prepackaged software products over time, ${ }^{13}$ particularly when new product introductions do not result in substantial price changes. ${ }^{14}$

Because of the widely recognized potential understatement of true price declines (or overstatement of true price increases) as measured by matched-model price indexes, in 2000 the U.S. Bureau of Economic Analysis began to make a "bias-adjustment" to the BLS prepackaged

\footnotetext{
10 Within-company weights can change annually, however, as a company's product mix undergoes sales variations.

11 http://www.bls.gov. Monthly BLS index values for September through December 2003 are preliminary and are subject to revision.

12 As mentioned above however, Harhoff and Moch [1997] report results contrary to this general finding.

13 On this, see Oliner and Sichel [1994] and Gordon [1994].

14 Triplett [2003], chs. 3, 5.
} 
software producer price index. ${ }^{15}$ The adjustment is based on the following calculation: Grimm and Parker [2000] compare two sets of indexes over the 1985 to 1993 time period: (1) the Oliner and Sichel [1994] matched-model price indexes for spreadsheets, word processors, and databases; and (2) a BEA hedonic price index for spreadsheets and word processors. ${ }^{16}$ The average annual difference between these two sets of price indexes over the 1985 to 1993 time period is -6.3 percent for spreadsheets and word processors. Therefore, when compiling and publishing its quarterly measures of U.S. real gross domestic product and real gross product by industry, the BEA calculates its bias adjustment as one-half of this -6.3 percent annual difference, or -3.15 percent annually.

\section{Hedonic Price Indexes for Personal Computer Operating Systems and Productivity Suites}

\section{Data Sources}

The operating systems analyzed in this study include those of Microsoft (MS DOS, Windows), IBM (PC DOS, OS/2), and DRI (DR DOS). For productivity suites, we measure quality-adjusted price changes for products from a number of manufacturers, including Microsoft (Works, Office), Lotus (Symphony), Ashton Tate/Borland (Framework), IBM (SmartSuite), and the WordPerfect Corporation (WordPerfect Suite). Our price data come from monthly editions of the personal computer magazine PC World from July 1987 to December 2000 for operating systems, ${ }^{17}$ and for productivity suites, from July 1984 to December 2000. We collected advertised price data for each personal computer operating system and productivity suite product that appeared in the advertisements of the monthly issues of PC World. We confined our attention to advertisements that were at least one-quarter page in size. The prices used in this analysis are representative primarily of retail brick-and-mortar and mail-order outlets. Information on the product name, version number (where available), and date of the

15 As stated in Grimm and Parker [2000], “....[a]n annual bias adjustment is made because it is likely - assuming less than complete market equilibrium - that matched-model indexes understate quality-adjusted price declines; quality improvements, such as enhanced power and performance, tend to be introduced in new versions of software, so they are not captured by the matched-model estimates." (p. 15). A further discussion of the BEA's software price estimates is found in Eugene P. Seskin [1999].

16 The BEA hedonic price index is an extension of research performed by Gandal [1994], Brynjolfsson and Kemerer [1996], and McCahill [1997].

$17 \quad$ Price quotes for operating systems were not available from PC World advertisements prior to 1987. 
advertisement was also collected. We confined the scope of our price coverage to full versions because of spotty and intermittent coverage of upgrades. Information on any relevant discounts or rebates, taxes, and shipping charges was also collected. The prices used in this analysis are net of discounts and rebates.

In collecting information on product attributes, we consulted numerous sources. We utilized information from a variety of product reviews (such as those contained in the monthly editions of PC World and PC Magazine), various Internet websites, and software product manuals. Many of the attributes are binary in nature, e.g., whether or not a particular operating system has a graphical user interface. Other attribute measures are continuous, e.g., the number of processors an operating system can use simultaneously. The attribute database was constructed so as to ensure a consistent set of attributes existed over time. A summary of the attribute information used in the hedonic regressions is contained in Table 2 (for operating systems) and Table 3 (for productivity suites), including mean, minimum, and maximum values of the various attribute variable measures. While most attribute variables are readily interpretable, several are worth discussing in greater detail.

In this paper, we attempt to identify and measure the presence of network effects among prepackaged software products and estimate their impact on quality-adjusted prices. For operating systems, we measure the degree of compatibility of the given operating system. First, we consider the degree of connectivity of the operating system, i.e., whether the operating system supports built-in networking or is USB compatible ("CONNECT"). Second, we consider the number of file systems with which the given operating system is compatible ("FILESYS"). Finally, we consider the number of platforms with which the operating system is compatible ("PLATFORM"). We include these measures as explanatory variables in our hedonic price equations. The time series of values taken by the CONNECT variable (included in our Base Case regression, see section IV.3 below) is shown in Figure 1. Note that, on average, this variable increases over time as operating systems' built-in networking capabilities improve over the 1987 to 2000 time period. As described below, we also estimate versions of these hedonic equations where we exclude such network-effects variables from the regressions.

For productivity suites, we construct a measure of the degree of integration of the product with respect to its component applications that we refer to as an "absolute integration score." We define a productivity suite to be fully integrated if each component of the suite is compatible 
with each other in the sense of allowing data interchange between the component applications. As an example of full integration, for Microsoft Office, tables or charts created in Excel can be embedded in Word, and vice versa.

If a productivity suite contains four applications, then the maximum absolute integration value it can attain is 12 (i.e., each application allows for data interchange with each of the other three applications in the productivity suite). Our absolute integration score expresses the integration value of a particular product as a fraction of the maximum possible integration value over all products in our data. In our analysis the maximum possible integration value is 30 , i.e., a productivity suite with six fully integrated component applications. Continuing our example of a productivity suite with four fully integrated component applications, the absolute integration score is 0.4 , i.e., $12 / 30$. The time series of values of the average absolute integration score over time is shown in Figure 2. Note that, on average, productivity suites have become more integrated over time.

\section{Econometric Specification Issues}

We employ the same general hedonic regression specification when estimating changes in the quality-adjusted prices of both personal computer operating systems and productivity suites over time. The dependent variable is the natural logarithm of the price from each advertisement for each product in a given quarter. As discussed below, in some cases we averaged a product's price over all advertisements of that product appearing in that quarter, and in other cases we treated each advertised price as a separate observation.

In addition to the quality attribute variables described in Tables 2 and 3, common quarterly time dummy variables (across years) and annual time dummy variables were added as explanatory variables. Thus our Base Case regression takes the form:

$$
\ln p=\alpha+\beta_{i} X_{i}+\beta_{y} D_{y}+B_{q} D_{q}+\varepsilon
$$

where:

$p=$ Advertised price for a given product, quarter, and advertisement;

$\beta_{i} \quad=$ Regression coefficients for $i$ quality characteristics, $i=1, \ldots n$;

$\beta_{y}=$ Regression coefficients for 13 or 16 annual dummy variables (1988 to 2000 for operating systems, 1985 to 2000 for productivity suites);

$\beta_{q}=$ Regression coefficients for three quarterly dummy variables (quarters 2, 3, 4); 
$\alpha \quad=$ Intercept term, representing reference case (1987 for operating systems, 1984 for productivity suites, and zero values of other indicator variables); and

$\varepsilon \quad=$ Independently distributed random disturbance term.

We refer to Eqn. (1) as our Base Case hedonic regression, which also includes measures of connectivity and product integration, respectively, for operating systems and productivity suites. We also estimated a version of (1) that omitted the measures of compatibility ("No Compatibility") and product integration ("No Integration"). In addition, we estimated parameters in a number of alternative specifications to Eqn. (1). A fully temporally parameterized ("Fully Parameterized") version of Eqn. (1) was also estimated, using separate quarterly dummy variables for each quarterly time period, instead of restricting the quarterly coefficients to be equal across years.

Note that ordinary least squares ("OLS") estimation of parameters in the Base Case specification can be envisaged as weighting a product's price by the number of times its advertisement is observed that quarter. Such parameter estimation is efficient under the assumption of homoskedasticity of the disturbances; if these disturbances are heteroskedastic, however, the OLS standard error estimates are biased. Therefore, the standard error estimates reported here are White-corrected heteroskedastic-consistent standard errors.

The fact that some products are advertised more frequently than others suggests an alternative specification that involves dealing with a differing type of heteroskedasticity among the residuals. In particular, we specify and estimate parameters in an alternative specification where the dependent variable is the logarithm of the arithmetic mean of the advertised price of each product observed during that quarter, i.e., the advertised price of each product averaged over all advertisements for that product in a given quarter ("Quarterly Average"), where this quarterly average price is then transformed logarithmically. Relative to the Base Case, this specification reduces the number of observations employed in the estimation, and therefore tends to downweight products whose advertised prices are observed more frequently.

As yet another alternative, we employed intuition based on the Dorfman and Steiner [1954] theorem that relates the optimal ratio of dollar advertising to sales revenue to the ratio of marketing and (the absolute value) of the price elasticities of demand for a firm facing a downward sloping demand curve. To the extent such a relationship holds here, if one wants to 
obtain sales-weighted hedonic price coefficients, one could approximate this by weighting the $\log$ quarterly average prices (from the Quarterly Average specification) by the number of advertisements observed that quarter. This raises, of course, the issue of whether one wants to use sales weighted or unweighted hedonic parameter estimates. This is a longstanding issue in hedonic price analyses; for recent discussions, see Triplett [2003] and Diewert [2003]. Rather than taking a definitive stand on this long-simmering dispute, here we merely report the sensitivity of our hedonic price coefficient estimates to use of alternative weighting schemes. Specifically, we report a Weighted Least Squares ("WLS") version of the Quarterly Average specification where the weights are the number of advertisements appearing for a given product in a given quarter.

For completeness, we also specify and estimate a fixed-effects ("Fixed Effects") variant of the Quarterly Average model, where each distinct product (e.g., Microsoft Office 2000, Microsoft Windows 98) is assigned a separate dummy variable, and while annual and quarterly time dummy variables are also incorporated as regressors, none of the quality attribute measures is included as a regressor. This Fixed-Effects specification has been advocated by Aizcorbe, Corrado, and Doms [2003], who argue that when prices are observed at relatively short time intervals (e.g., monthly or quarterly rather than annually), and when each product's price is observed frequently, then a fixed-effects specification without quality attribute variables will approximate rather closely the traditional hedonic specification.

It is worth commenting briefly on this Fixed-Effects specification. As discussed in contemporary econometrics textbooks (see, for example, Wooldridge [2000], ch. 14, "Advanced Panel Data Methods"), use of a fixed-effects specification is tantamount to time demeaning each cross-sectional variable (in our context, each distinct software product), and doing pooled OLS using the time-demeaned observations. For these reasons, the resulting estimates are typically called "within-estimators," for they capture the time variation within each distinct software product. Since they focus only on within-product variation, these fixed-effects specification estimates can in fact be viewed as being analogous to matched-model price index computations; indeed, it is reasonable to think of these fixed-effects specification estimates as being "matchedmodel econometric estimates."

One other point worth making in this context is that if a model is observed only once, and if it is assigned a fixed effect, then of course the fit of the regression equation will be perfect for 
all such only once-observed products, for the implicit product-specific intercept term will just equal what would otherwise be the residual between the observed and predicted price. An implication of this is that OLS parameter estimates for all the remaining estimated coefficients will be numerically invariant regardless of whether or not these only once-observed products are included in the estimation. ${ }^{18}$ Since the fixed-effects specification parameter estimates are invariant in this case, in essence the specification is not making use of any information obtained in the only once-observed products. ${ }^{19}$ Our intuition, therefore, is that when the proportion of only once-observed products is rather high (as it might be, for example, in annual data for personal computer hardware manufacturers), one would expect the fixed-effects econometric specification to generate parameter estimates for the time dummies whose time trend approximated that of the matched-model price index procedures. If, however, the proportion of only once-observed products in the sample is rather low, then the fixed-effects econometric and matched-model price index procedures could yield rather differing AAGRs.

Finally, as noted previously, in recent years attention has focused on issues regarding the interpretation of intertemporal instability of estimated hedonic parameters. In fact, this issue already concerned Griliches in his classic 1961 study, where parameters of the automobile model's weight varied considerably over time. To check for possible parameter instability over time, we divide the 1984 to 2000 productivity suite and the 1987 to 2000 operating system samples into approximate halves, and report on implications of this for the estimation of qualityadjusted price declines.

\section{Price Indexes for Personal Computer Operating Systems}

\section{Hedonic Price Indexes}

Parameter estimates for the Base Case and various alternative specification regressions for personal computer operating systems are presented in Table 4. Recall that in the Base Case, each advertisement for each product is treated as a separate observation, e.g., if there are ten advertisements for Windows 95 in a given quarter then this product appears ten times in the regression for that quarter (with the same product attributes as explanatory variables). The Base

For a numerical demonstration of this, see Exercise 7 in Berndt [1991], ch. 3, pp. 48-50.

19

For a more formal discussion, see Wooldridge [2000], pp. 448-449. 
Case also employs common quarterly dummy variables for each of the years 1988 through 2000, which is more parsimonious in the parameters than the Fully-Parameterized model, whose estimates are given in the second set of columns. The full-sample regressions in the first three sets of columns each have sample sizes consisting of 340 individual observations.

As seen in the first three sets of columns, parameter estimates for each of the five product attributes (presence of graphical user interface, presence of hardware auto-detection, extent of multitasking, extent of multiprocessing, and presence of full-screen text editor) are positive, consistent with the view that the presence of, or increase in such attributes is associated with higher consumer valuations. Except for the multitasking measure, each is also statistically significant, with $\mathrm{p}$-values $<0.05$. The coefficient on the CONNECT variable (representing the sum of dummy variables for operating systems that support built-in networking and USB compatibility) is positive and highly significant, indicating positive network effects among personal computer operating systems. ${ }^{20}$ The robustness on the various quality attribute coefficients with respect to the Base Case estimates carries over to the Quarterly Average and WLS specifications, although in the Quarterly Average case the coefficient estimates on the GUI, AUTO_HW and MULTI and CONNECT variables become statistically insignificant, and in the WLS case the coefficient estimates on the GUI, AUTO_HW and MULTI variables become insignificant. However, all parameter estimates remain positive.

Turning now to coefficient estimates on the annual and quarterly time dummy variables, the most striking result in Table 4 is the relative robustness of the implied AAGRs of price change across the entire range of alternative specifications. As seen in the bottom rows of Table 4, over the full 1987 to 2000 time period, AAGRs are -16.83 percent for the Base Case, -17.52 percent with the Fully-Parameterized specification, -15.72 percent for the Base Case with compatibility measures omitted as regressors, -16.21 for the Quarterly Average, and -16.90 percent for WLS. In terms of comparisons of AAGRs in the first and second half of the full between FILESYS and CONNECT is 0.78, and that between PLATFORM and CONNECT is 0.77. When these three variables are all included as regressors, the estimate on FILESYS becomes negative and significant, although the resulting AAGR over the 1987 to 2000 time period changes to -18.16 percent, compared to -16.83 percent for the Base Case regression. We also estimated a variation of the Base Case excluding the FILESYS variable and kept both CONNECT and PLATFORM as regressors. The parameter estimate on PLATFORM was negative and significant and that on CONNECT was positive and significant. The resulting AAGR for 1987 to 2000 was -17.18 percent. For a discussion of parameter estimates in hedonic regressions having the "wrong" sign, see Pakes [2003]. 
1987 to 2000, for the Base Case regression price declines are greater in 1993 to 2000 compared to 1987 to 1993 (18.40 percent compared to 14.96 percent), and this inequality holds across all specifications.

As a check on the temporal parameter stability of our hedonic regressions, we reestimated our Base Case regression for the two sub-periods 1987 to 1993, and 1993 to 2000. The resulting AAGRs from the two separate regressions were -14.71 percent for 1987 to 1993 and -18.57 percent for 1993 to 2000 . These compare with the AAGRs of -14.96 and -18.40 percent, respectively, for the periods 1987 to 1993 and 1993 to 2000 based on the regression using data for the entire 1987 to 2000 time period. Thus the resulting AAGRs are reasonably robust over these different specifications.

Finally, AAGRs from the Fixed-Effects regression specification are presented in the bottom rows of the final set of columns in Table. 4. Over the entire 1987 to 2000 time period, the AAGR at -14.63 percent represents the smallest rate of price decline in the various specifications, although the difference in most cases is a little over 1-2 percentage points. However, averaged separately over the 1987 to 1993 and 1993 to 2000 time periods, the FixedEffects specification yields a much smaller rate of price decline for 1987 to 1993, -10.0 percent, than over the later 1993 to 2000 time frame, -18.41 percent. Price index values over the entire 1987 to 2000 time period, based on the various regressions and on the traditional matched-model price index procedure (discussed below), are presented in Appendix A.

\section{Matched-model vs. Hedonic Price Indexes}

We now turn to a comparison of time trends of the hedonic-based price indexes relative to the more traditional matched-model price indexes. Analogous to the fixed-effects specification, in the context of personal computer operating systems, a matched-model price index would compare the prices of Windows 95 over time, but the prices of Windows 95 would not be compared with those of, say, Windows 98 since such products would be considered to be different. Examples of such matched-model price indexes for personal computer software have been reported by Oliner and Sichel [1994], Prud'homme and Yu [2002] and Abel, Berndt, and White [2003]. We have computed a matched-model price index for personal computer operating systems based on a chained geometric average of quarterly average price relatives over time, as discussed in Diewert [1995]. Since we did not have information on unit shipments, this index is 
an unweighted price index. The resulting index declines at an AAGR of 7.02 percent over the 1987 to 2000 time period. Note that this matched-model price index is calculated using the same underlying data as that used in the Quarterly Average regression, rather than using individual price quotes. Notably, as shown in Figure 3, the Quarterly Average hedonic declines at a greater rate of 16.21 percent between 1987 and 2000, more than double the matched-model rate of price decline of 7.02 percent. This approximate 9 percentage point differential between the hedonic and matched-model AAGRs compares to the 3.15 percent annual adjustment the BEA applies to the BLS prepackaged software PPI. ${ }^{21}$ When the matched-model price index is recomputed as a chained Fisher price index (using the number of advertisements as weights, as in the WLS regression), the resulting AAGR is very similar. Finally, an index of simple average prices that makes no control for changes in product quality over time, declines at approximately 1.16 percent over the 1987 to 2000 time period. Note that this simple arithmetic average price suffers from the drawback that the prices of Windows 2000, for example, are compared with those of MS-DOS - which are very different products in terms of features and functionality.

\section{Price Indexes for Productivity Suites}

\section{Hedonic Price Indexes}

We estimate parameters from a hedonic regression for productivity suites, analogous to that for personal computer operating systems. As in the case of operating systems, the natural logarithm of the individual advertised prices from advertisements in monthly editions of $P C$ World were used as the dependent variable in the Base Case hedonic regression. To be considered a productivity suite, a product must have both a word processor and a spreadsheet as components. Therefore, the presence of additional component application products as well as the absolute integration score are used as independent variables. Results from our Base Case regression consisting of 1,717 individual observations are shown in Table 5.

The Base Case, Fully Parameterized, Quarterly Average, and WLS regressions each contain nine quality attribute variables in addition to the absolute integration score. In all cases, 
the coefficient estimate on the absolute integration score is positive and highly significant. ${ }^{22}$ As seen in the various columns of Table 5, parameter estimates on the DB (database) attribute measure are sensitive to whether the absolute integration score measure is included in the hedonic regression; estimates on the DB variable change sign from negative to positive when the absolute integration measure is excluded and is statistically significant in this regression. Base Case parameter estimates on the GRPH, PRES, and PUB variables are positive and significant (that for GRPH being particularly significant), while those on the DB, COMM, CAL, REFEREN, FINANCE and SPEECH variables are negative.

While estimates on the quality attribute variables are somewhat sensitive to the choice of specification, this is clearly not the case for coefficients on the year and quarterly dummy variables. Not only are most of the annual time dummy variables negative and statistically significant with p-values $<0.01$, but remarkably, across the six hedonic price regressions, AAGRs of estimated quality-adjusted price changes between 1984 to 2000 range only from 14.97 percent to -16.25 percent per year; the Fixed-Effects specification is also reasonably close at -13.00 percent per year. ${ }^{23}$

This robustness of estimates of AAGRs of quality-adjusted price changes holds reasonably well even when one examines sub-periods. As shown in the bottom rows of Table 5, for the six hedonic price equation specifications, average annual price changes in the 1984 to 1992 half of the sample range between -11.49 and -14.56 percent, but are all smaller than the declines of -17.91 percent to -18.43 percent obtained during the 1992 to 2000 half of the sample. While this inequality of AAGRs between sub-periods still holds for the fixed-effects specification, here it becomes much larger, being -0.69 percent in the 1984 to 1992 time period, and -23.78 percent in the more recent 1992 to 2000 time frame. Price index values over the

22 We also estimated a version of the Base Case regression that excluded the absolute integration score as a regressor ("No Integration"). The resulting AAGR of this regression dropped to -14.97 percent over the 1984 to 2000 time period, compared to -15.35 percent when the absolute integration score is included. Since we were unable to define an absolute integration score for every productivity suite in our sample, we had an additional 889 observations with undefined absolute integration scores. When we estimated the No Integration hedonic based on the larger sample of 2,606 observations, the resulting AAGR for 1984 to 2000 was virtually unchanged at -15.03 percent ( -14.97 percent for the smaller sample).

23 The fixed-effects specification was also estimated over the larger sample for which some productivity suites did not have a defined absolute integration score. The resulting AAGR increased from -13.00 to -15.84 percent. 
entire 1984 to 2000 time period, for all econometrically estimated regressions, as well as that based on the traditional matched-model price index procedure, are presented in Appendix B.

As a check on the temporal parameter stability of our hedonic regressions, we reestimated our Base Case regression for the two sub-periods 1984 to 1992 and 1992 to 2000. The resulting AAGRs from the two separate regressions were -8.88 percent for 1984 to 1992 and 17.90 percent for 1992 to 2000 . These compare with the AAGRs of -12.31 percent and -18.29 percent, respectively, for the periods 1984 to 1992 and 1992 to 2000 based on the regression using data from the entire 1984 to 2000 time period. Thus the resulting AAGRs are reasonably robust over these different specifications.

\section{Matched-model vs. Hedonic Price Indexes}

We have also computed matched-model price indexes for the productivity suites, again based on a chained geometric average of quarterly price relatives for matched products. We find that with the matched-model procedure, prices fall at an annual rate of 15.36 percent, a slightly lower decline than the corresponding Quarterly Average hedonic regression which yields declines in quality-adjusted prices of 16.25 percent per annum (see bottom rows of Table 5, Appendix B and Figure 4). Although it is well documented that matched-model price indexes tend in general to decline less rapidly (rise more quickly) than those based on a corresponding hedonic regression, we find that for the 1992 to 2000 time period, the matched-model index declines at a rate of 28.69 percent per annum, greater than the 17.91 percent decline in the corresponding hedonic price index. ${ }^{24}$ The only other such finding in the literature of which we are aware is that reported by Harhoff and Moch [1997]. Although our result may appear slightly counterintuitive, it is largely driven by the huge declines in the prices of such products as WordPerfect Suite and Lotus SmartSuite, whose retail prices were slashed considerably in the late 1990s in an effort to boost sales. When the AAGRs are computed over the shorter time period 1984 to 1998, the declines in prices are 15.41 and 3.22 percent for the hedonic and matched-model price indexes, respectively, consistent with a priori expectations. A chained

For completeness, the matched-model price indexes have also been calculated over the larger sample including those productivity suites for which we did not have a defined product integration score $(n=347)$. The resulting AAGR is almost 2 percentage points lower over the 1984 to 2000 time period (-17.22 compared to -15.36 percent). 
Fisher price index version of the matched-model price index using the number of advertisements as weights resulted in almost no change in the AAGRs.

As shown in Figure 4, we have also computed an index of the average price level (normalized to equal 100 in 1984). This average price for productivity suites declines at an average rate of 7.18 percent per annum between 1984 and 2000. Note that this average price does not account for the fact that Lotus SmartSuite, for example, is a different product from Office 98 Professional, since all products are treated symmetrically in computing the average. Furthermore, average price levels do not take into account the changes in quality of the productivity suites over time; quality-adjusted prices decline, on average, over 10 percentage points more than average price levels between 1984 and 2000.

\section{Conclusion}

Rapid technological advances in personal computer hardware have lead to significant improvements in the quality of the software used by consumers. Nowhere is this change in quality more clear than for personal computer operating systems, where esoteric character-based operating systems have been replaced by powerful operating systems with user-friendly graphical user interfaces and advanced networking capabilities. For applications, feature-rich software products previously sold in stand-alone form have increasingly been added to fully integrated productivity suites.

In this paper, we have augmented the relatively sparse literature on quality-adjusted personal computer software price indexes to include personal computer operating systems (1987 to 2000) and productivity suites (1984 to 2000). Although we estimate a variety of alternative hedonic specifications, we obtain remarkably robust estimates of annual quality-adjusted price declines in these software product categories. Specifically, for personal computer operating systems, we find AAGRs ranging between -15 and -18 percent, while for productivity suites they generally vary between -13 and -16 percent. For both product categories, the rates of price decline are larger in the last half of the sample than in the first half. Fixed-effects models also tend to yield slightly smaller rates of price decline than traditional hedonic-attribute specifications. Finally, in most but not all cases, hedonic price indexes are associated with greater rates of price decline than are those based on matched-model price index computations. 
Among the explanatory variables we employ in our hedonic regressions are several variables constructed to capture the presence of network effects for personal computer operating systems, such as connectivity and compatibility, and product integration among the components of productivity suites. We generally find positive and statistically significant coefficient estimates on these variables, indicating that consumers place a value on software products that exhibit a high degree of compatibility and product integration. These findings are consistent with the small but growing literature seeking to identify the presence of network effects in information technology markets.

As with previous studies of personal computer software prices, we employ data covering retail sales. It is worth noting, however, that sales in this channel of distribution have become increasingly unrepresentative of prepackaged personal computer software transactions, which are now most commonly through large-account distributors and OEMs. Therefore, extending this line of research to include the prices from all channels of distribution used in the prepackaged software industry is an important, but potentially difficult, area for future research. 


\section{REFERENCES}

Abel, Jaison R., Ernst R. Berndt, and Alan G. White [2003], "Price Indexes for Microsoft's Personal Computer Software Products," Cambridge, MA: National Bureau of Economic Research, Working Paper No. 9966, September.

Aizcorbe, Ana M. [2003a], "The Stability of Dummy Variable Price Measures Obtained from Hedonic Regressions,” Washington DC: Federal Reserve Board, draft manuscript, January 2.

Aizcorbe, Ana M. [2003b], "Hedonic Regression Coefficients as Averages of Reduced Form Coefficients," Washington DC: Federal Reserve Board, draft manuscript, October 23.

Aizcorbe, Ana M. [2003c], "Price Indexes for Intermittent Purchases: Are Price Declines for High-Technology Goods Overstated?" Washington DC: Bureau of Economic Analysis, draft manuscript, December.

Aizcorbe, Ana M., Carol Corrado, and Mark Doms [2003], "When Do Matched-Model and Hedonic Techniques Yield Similar Price Measures?" Federal Reserve Bank of San Francisco, Working Paper No. 2003-14, June 16.

Berndt, Ernst R. [1991], The Practice of Econometrics: Classic and Contemporary, Reading, MA: Addison-Wesley.

Berndt, Ernst R. and Zvi Griliches [1993], "Price Indexes for Microcomputers: An Exploratory Study," in Murray Foss, Marilyn Manser and Allan Young, eds., Price Measurements and Their Uses, Chicago: University of Chicago Press for the National Bureau of Economic Research, pp. 63-93.

Berndt, Ernst R., Zvi Griliches, and Neal J. Rappaport [1995], "Econometric Estimates of Price Indexes for Personal Computers in the 1990s," Journal of Econometrics, 68, pp. 243-268.

Berndt, Ernst R. and Neal J. Rappaport [2001], "Price and Quality of Desktop and Mobile Personal Computers: A Quarter Century Historical Overview," American Economic Review, 91(2), May, pp. 268-273.

Berndt, Ernst R. and Neal J. Rappaport [2002], "Hedonics for Personal Computers: A Reexamination of Selected Econometric Issues," Cambridge, MA: MIT Sloan School of Management, draft manuscript, July 18.

Boskin, Michael J., Ellen R. Dulberger, Robert J. Gordon, Zvi Griliches, and Dale W. Jorgenson [1996], Toward a More Accurate Measure of the Cost of Living, Final Report to the U.S. Senate Finance Committee from the Advisory Commission to Study the Consumer Price Index, Washington DC: US Government Printing Office. 
Brynjolfsson, Erik and Chris F. Kemerer [1996], "Network Externalities in Microcomputer Software: An Econometric Analysis of the Spreadsheet Market," Management Science, 42, pp. 1627-1647.

Conference Board [1999], Measuring Prices in a Dynamic Economy: Re-Examining the CPI, New York.

Court, Andrew T. [1939], "Hedonic Price Indexes with Automotive Examples," in The Dynamics of Automobile Demand, New York: The General Motors Corporation, pp. 99-117.

Diewert, W. Erwin [1995], "Axiomatic and Economic Approaches to Elementary Price Indexes," UBC Department of Economics Discussion Paper No. 95-01.

Diewert, W. Erwin [2003], "Hedonic Regressions: A Consumer Theory Approach," in Robert C. Feenstra and Matthew D. Shapiro, eds., Scanner Data and Price Indexes, Chicago: University of Chicago Press for the National Bureau of Economic Research, pp. 317-348.

Dorfman, Robert and Peter O. Steiner [1954], "Optimal Advertising and Optimal Quality," American Economic Review, 44:5, December, 826-836.

Feenstra, Robert C. [1995], "Exact Hedonic Price Indexes," Review of Economics and Statistics, 77(4), November, pp. 634-653.

Gandal, Neil [1994], "Hedonic Price Indexes for Spreadsheets and an Empirical Test of Network Externalities," RAND Journal of Economics, 25, pp. 160-170.

Gandal, Neil [1995], "Competing Compatibility Standards and Network Externalities in the PC Software Market," The Review of Economics and Statistics, 77, pp. 599-608.

Griliches, Zvi [1961], "Hedonic Price Indexes for Automobiles: An Econometric Analysis of Quality Change," in The Price Statistics of the Federal Government, General Series No. 73, New York: Columbia University Press for the National Bureau of Economic Research, pp. 137-196.

Grimm, Bruce and Robert Parker [2000], "Software Prices and Real Output: Recent Developments at the Bureau of Economic Analysis," paper presented at the National Bureau of Economic Research, Program on Technological Change and Productivity Measurement, Cambridge, MA, March 17.

Grohn, Andreas [n.d.], "Network Effects in PC Software: An Empirical Analysis," unpublished manuscript, Kiel, Germany: Kiel University.

Gordon, Robert J. [1994], “'Comment' on Oliner and Sichel," Brookings Papers on Economic Activity, 2, pp. 324-328.

Harhoff, Dietmar and Dietmar Moch [1997], "Price Indexes for PC Database Software and the Value of Code Compatibility,” Research Policy, 26, pp. 509-520. 
Heravi, Saeed and Mick Silver [2002], "On the Stability of Regression Coefficients and their Implications for Quality-Adjusted Price Change Measurement," paper presented at the NBER Summer Institute, Cambridge, MA.

Lynch, Brian D., H. Raghav Rao, and Winston T. Lin [1990], "Economic Analysis of Microcomputer Hardware," Communications of the ACM, 33, pp. 119-129.

McCahill, Robert J. [1997], “An Hedonic Study of Prepackaged Software,” Master's Thesis, Department of Economics, Virginia Polytechnic Institute and State University, Blacksburg, VA.

McKinsey Global Institute [2001], "United States Productivity Growth, 1995-2000," Washington DC: McKinsey Global Institute, October.

National Academy of Sciences [2002], At What Price? Conceptualizing and Measuring the Costof-Living and Price Indexes, Panel on Conceptual, Measurement and Other Statistical Issues in Developing Cost-of-Living Indexes, Charles Schultze and Christopher Mackie, eds., Committee on National Statistics, National Research Council.

Oliner, Stephen D. and Daniel E. Sichel [1994], “Computers and Output Growth Revisited: How Big is the Puzzle?" Brookings Papers on Economic Activity, 2, pp. 273-330.

Pakes, Ariel [2003], “A Reconsideration of Hedonic Price Indexes with an Application to PC's," American Economic Review, 93(5), December, pp. 1578-1596.

Prud-homme, Marc and Kam Yu [2002], "A Price Index for (Prepackaged) Computer Software Using Scanner Data," draft manuscript, Ottawa: Statistics Canada, Prices Division, July.

Rao, H. Raghav and Brian D. Lynch [1993], "Hedonic Price Analyses of Workstation Attributes," Communications of the ACM, 36, pp. 95-102.

Seskin, Eugene P. [1999], "Improved Estimates of the National Income and Products Accounts for 1959 to 1998: Results of the Comprehensive Revision," Survey of Current Business, 79, pp. 15-39.

Silver, Mick and Saeed Heravi [2002], "Why The CPI Matched Models Method May Fail Us: Results from an Hedonic and Matched Model Experiment Using Scanner Data," paper presented at the Brookings Institution, Workshop on Hedonic Price Indexes: Too Fast, Too Slow, or Just Right?" February.

Triplett, Jack E. [2003], "Handbook on Quality Adjustment of Price Indexes for Information and Communication Technology Products," Directorate for Science, Technology and Industry, Industrial Committee, Paris, OECD. Draft manuscript, Washington DC: The Brookings Institution, December 31.

United States Bureau of Labor Statistics, www.bls.gov. 
Waugh, Frederick V. [1928], "Quality Factors Influencing Vegetable Prices,” Journal of Farm Economics, 10, pp. 185-196.

Wooldridge, Jeffrey M. [2000], Introductory Econometrics: A Modern Approach, South-Western College Publishing, A Division of Thomson Learning. 
Table 1

Summary of Prepackaged Software Price Measurement Research

\begin{tabular}{|c|c|c|c|c|c|}
\hline Author(s) & Products Considered & Method Used & Country & Years Covered & Annual Price Change \\
\hline Gandal [1994] & Spreadsheets & Hedonic & U.S.A & $1986-1991$ & $-15 \%$ \\
\hline \multirow[t]{3}{*}{ Oliner and Sichel [1994] } & Word Processors & Matched-model & U.S.A & 1985-1993 & $-2.6 \%$ \\
\hline & Spreadsheets & Matched-model & U.S.A & 1985-1993 & $-4.5 \%$ \\
\hline & Databases & Matched-model & U.S.A & 1985-1993 & $-4.7 \%$ \\
\hline \multirow[t]{2}{*}{ Gandal [1995] } & Spreadsheets & Hedonic & U.S.A & 1989-1991 & $-4.4 \%$ \\
\hline & \begin{tabular}{|l|} 
Databases \\
\end{tabular} & Hedonic & 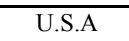 & 1989-1991 & $-1.5 \%$ \\
\hline Grohn [n.d.] & Word Processors & Hedonic & Germany & $1985-1995$ & $-11.3 \%$ to $-36.9 \%$ \\
\hline Brynjolfsson and Kemerer [1996] & Spreadsheets & Hedonic & U.S.A & $1987-1992$ & $-14.8 \%$ to $-16.5 \%$ \\
\hline \multirow[t]{2}{*}{ McCahill [1997] } & Spreadsheets & Hedonic & U.S.A & 1986-1993 & $-9.0 \%$ to $-16.9 \%$ \\
\hline & Word Processors & Hedonic & U.S.A & 1985-1994 & $-15.1 \%$ to $-18.5 \%$ \\
\hline \multirow[t]{2}{*}{ Harhoff and Moch [1997] } & Databases & Hedonic & Germany & 1986-1994 & $-7.41 \%$ \\
\hline & Databases & Matched-model & Germany & 1986-1994 & $-9.25 \%$ \\
\hline Grimm and Parker [2000] & General & Interpolation, Matched-model, and Hedonic & U.S.A & $1959-1998$ & $-10.9 \%$ \\
\hline McKinsey Global Institute (2001) & Operating Systems & Function points & U.S.A & 1988-1998 & $-11.7 \%$ \\
\hline Prud'homme and Yu [2002] & General & Matched-model & Canada & $1996-2000$ & $-4.4 \%$ to $-7.9 \%$ \\
\hline \multirow[t]{4}{*}{ Abel, Berndt, and White [2003] } & Word Processors & Matched-model & U.S.A & 1993-2001 & $-10.6 \%$ \\
\hline & Spreadsheets & Matched-model & U.S.A & $1993-2001$ & $-8.2 \%$ \\
\hline & Productivity Suites & Matched-model & U.S.A & $1993-2001$ & $-4.8 \%$ \\
\hline & Desktop Operating Systems & Matched-model & U.S.A & $1993-2001$ & $-0.4 \%$ \\
\hline BLS [2003] & General & Matched-model & U.S.A & $1997-2003$ & $-1.1 \%$ \\
\hline
\end{tabular}


Table 2

Attributes of Personal Computer Operating Systems

\begin{tabular}{|c|c|c|c|c|c|c|}
\hline Variable & Abbreviation & Function & Description & Minimum & Maximum & Mean \\
\hline Graphical User Interface & GUI & $\begin{array}{l}\text { A GUI allows a user to access information and } \\
\text { perform operations by pointing and clicking with a } \\
\text { mouse. }\end{array}$ & $\begin{array}{l}\text { Takes on a value of } 1 \text { if the operating system supports } \\
\text { a GUI, else } 0 \text {. }\end{array}$ & 0.00 & 1.00 & 0.62 \\
\hline Hardware Auto-detection & AUTO_HW & $\begin{array}{l}\text { Hardware auto-detection allows a user to augment } \\
\text { existing personal computers with additional devices } \\
\text { without requiring manual installation of hardware and } \\
\text { drivers. }\end{array}$ & $\begin{array}{l}\text { Takes on a value of } 1 \text { if the operating system supports } \\
\text { hardware autodetection, else } 0 \text {. }\end{array}$ & 0.00 & 1.00 & 0.22 \\
\hline Multi-tasking & MULTI & $\begin{array}{l}\text { Cooperative multi-tasking allows a user to switch } \\
\text { between active tasks, but the switched-away task does } \\
\text { not continue to execute in the background. } \\
\text { Preemptive multi-tasking allows multiple tasks to } \\
\text { execute concurrently. }\end{array}$ & $\begin{array}{l}\text { Takes on a value of } 1 \text { if the operating system supports } \\
\text { cooperative multi-tasking, } 2 \text { if it supports preemptive } \\
\text { multi-tasking, else } 0 \text {. }\end{array}$ & 0.00 & 2.00 & 1.08 \\
\hline Multi-processing & SMP & $\begin{array}{l}\text { Multi-processing improves the speed of the operating } \\
\text { system. }\end{array}$ & $\begin{array}{l}\text { The number of processors that the operating system } \\
\text { can use simultaneously. }\end{array}$ & 1.00 & 2.00 & 1.19 \\
\hline Full-screen Text Editor & TXT_EDITOR & $\begin{array}{l}\text { Allows a user to view and edit and view a full screen } \\
\text { of text at one time. }\end{array}$ & $\begin{array}{l}\text { Takes on a value of } 1 \text { if the operating system has a full } \\
\text { screen text editor, else } 0 \text {. }\end{array}$ & 0.00 & 1.00 & 0.78 \\
\hline Application Platform Support/Compatibility & PLATFORM & $\begin{array}{l}\text { A personal computer operating system can be } \\
\text { compatible with DOS, Windows 16-bit, Windows 32- } \\
\text { bit, OS/2 32-bit, and/or Posix applications. }\end{array}$ & $\begin{array}{l}\text { The number of applications platforms with which the } \\
\text { operating system is compatible. }\end{array}$ & 1.00 & 4.00 & 2.27 \\
\hline Supported File Systems & FILESYS & $\begin{array}{l}\text { Allows a user to read data from FAT, FAT32, NTFS, } \\
\text { and/or HPFS file systems. }\end{array}$ & $\begin{array}{l}\text { The number of file systems with which an operating } \\
\text { system is compatible. }\end{array}$ & 1.00 & 3.00 & 1.32 \\
\hline Connectivity & CONNECT & Allows a user to have additional connectivity features. & $\begin{array}{l}\text { The sum of dummy variables indicating whether an } \\
\text { operating system supports built-in networking and/or } \\
\text { USB capability. }\end{array}$ & 0.00 & 2.00 & 0.47 \\
\hline
\end{tabular}

Sources:

1. $P C$ World magazine, 1987-2000

2. Various issues of PC Magazine, Internet websites, and software product manuals. 
Table 3

Attributes of Productivity Suites

\begin{tabular}{|c|c|c|c|c|c|c|}
\hline Variable & Abbreviation & \begin{tabular}{|c|} 
Function \\
\end{tabular} & \begin{tabular}{|c|} 
Description \\
\end{tabular} & Minimum & Maximum & Mean \\
\hline Absolute Integration Score & INT_ABS_SCORE & $\begin{array}{l}\text { Productivity suites with high integration scores are } \\
\text { highly compatible, allowing exchange of } \\
\text { datafifformation among components of the productivity } \\
\text { suite. }\end{array}$ & $\begin{array}{l}\text { Score indicates degree of integration among component } \\
\text { applications of a productivity suite, normalized between } \\
0 \text { and } 1 \text {. }\end{array}$ & 0.30 & 1.00 & 0.64 \\
\hline Database & DB & $\begin{array}{l}\text { A database application allows a user to manage and } \\
\text { analyze large datasets. }\end{array}$ & $\begin{array}{l}\text { Takes on a value of } 1 \text { if the productivity suite includes a } \\
\text { desktop database application, else } 0 \text {. }\end{array}$ & 0.00 & 1.00 & 0.92 \\
\hline Communications & COMM & $\begin{array}{l}\text { A communications application allows a user to } \\
\text { communicate with other users via e-mail, or by } \\
\text { providing a utility for connecting to a modem. }\end{array}$ & $\begin{array}{l}\text { Takes on a value of } 1 \text { if the productivity suite includes } \\
\text { an e-mmail communincations spplication, or a utility for } \\
\text { connecting to a modem, else } 0 \text {. }\end{array}$ & 0.00 & 1.00 & 0.98 \\
\hline Calendar & CAL & $\begin{array}{l}\text { A calendar application allows a user to track and } \\
\text { maintain appointments electronically. }\end{array}$ & $\begin{array}{l}\text { Takes on a value of } 1 \text { if the productivity suite includes a } \\
\text { calendar application, else } 0 \text {. }\end{array}$ & 0.00 & 1.00 & 0.23 \\
\hline Graphing & GRPH & $\begin{array}{l}\text { A graphing capability (either a separate graphing } \\
\text { application or included in another application allows a a } \\
\text { user to transform numerical data into charts and graphs. }\end{array}$ & $\begin{array}{l}\text { Takes on a value of } 1 \text { if the productivity suite includes } \\
\text { graphing capabilities, else } 0 .\end{array}$ & 0.00 & 1.00 & 0.99 \\
\hline Presentation & PRES & $\begin{array}{l}\text { A presentation application allows a user to transform } \\
\text { text and images into a presentation slide set. }\end{array}$ & $\begin{array}{l}\text { Takes on a value of } 1 \text { if the productivity suite includes a } \\
\text { presentation application, else } 0 \text {. }\end{array}$ & 0.00 & 1.00 & 0.15 \\
\hline Desktop Publishing & PUB & $\begin{array}{l}\text { A desktop publishing application allows a user to } \\
\text { control the type, graphics, layout and design of pages. }\end{array}$ & $\begin{array}{l}\text { Takes on a value of } 1 \text { if the productivity suite includes a } \\
\text { desktop publishing application, else } 0 \text {. }\end{array}$ & 0.00 & 1.00 & 0.04 \\
\hline$\overline{R e f e r e n c e}$ & REFEREN & $\begin{array}{l}\text { A reference application allows a user to access a digital } \\
\text { encylopedia. }\end{array}$ & $\begin{array}{l}\text { Takes on a value of } 1 \text { if the productivity suite includes a } \\
\text { reference application, else } 0 \text {. }\end{array}$ & 0.00 & 1.00 & 0.00 \\
\hline Personal Finance & FINANCE & $\begin{array}{l}\text { A personal finance application allows a user to track and } \\
\text { analyze personal finances such as cash holdings and } \\
\text { stocks. }\end{array}$ & $\begin{array}{l}\text { Takes on a value of } 1 \text { if the productivity suite includes a } \\
\text { personal finance application, else } 0 \text {. }\end{array}$ & 0.00 & 1.00 & 0.00 \\
\hline Speech Recognition & SPEEC & $\begin{array}{l}\text { A speech recognition capability allows a user to } \\
\text { communicate verbally with a productivity suite. }\end{array}$ & $\begin{array}{l}\text { Takes on a value of } 1 \text { if the productivity suite includes } \\
\text { speech recognition capabilities, else } 0 \text {. }\end{array}$ & 0.00 & 1.00 & 0.03 \\
\hline
\end{tabular}

Sources:
1. PC World

e, 1987-2000

2. Various issues of $P C$ Magazine, Internet websites, and software product manuals 
Table 4

Hedonic Regression Results for Personal Computer Operating Systems

\begin{tabular}{|c|c|c|c|c|c|c|c|c|c|c|c|c|}
\hline \multirow[b]{2}{*}{ Variable } & \multirow{2}{*}{\multicolumn{2}{|c|}{\begin{tabular}{l}
\multicolumn{2}{c}{ Base Case } \\
Coeff.
\end{tabular}}} & \multicolumn{2}{|c|}{ Fully Parameterized } & \multicolumn{2}{|c|}{ No Compatibility } & \multicolumn{2}{|c|}{ Quarterly Average } & \multicolumn{2}{|c|}{ WLS } & \multicolumn{2}{|c|}{ Fixed Effects } \\
\hline & & S.E. & Coeff. & S.E. & Coeff. & & Coeff. & S.E. & Coeff. & S.E. & Coeff. & S.E. \\
\hline Intercept & 3.7310 & $\begin{array}{ll}0.1026 & * * \\
*\end{array}$ & 3.6426 & $0.1051 * *$ & 3.5886 & $0.0967 * *$ & 3.8034 & $0.1682 * *$ & 3.7366 & 0.2675 ** & 4.5366 & $0.1186 * *$ \\
\hline GUI & 0.1646 & $0.0398 * *$ & 0.1934 & $0.0401 * *$ & 0.1655 & $0.0399 * *$ & 0.2280 & 0.1091 & 0.1643 & 0.1182 & & \\
\hline AUTO_HW & 0.3115 & $0.1397 *$ & 0.1073 & 0.1275 & 0.6276 & $0.0740 * *$ & 0.2372 & 0.2227 & 0.3045 & 0.2206 & & \\
\hline MULTİ & 0.0823 & 0.0538 & 0.0438 & 0.0618 & 0.0899 & 0.0524 & 0.0872 & 0.0920 & 0.0849 & 0.1040 & & \\
\hline SMP & 1.0443 & $0.0966 * *$ & 0.9967 & $0.1042 * *$ & 1.1760 & $0.0899 * *$ & 0.9409 & $0.1551 * *$ & 1.0430 & $0.1753 * *$ & & \\
\hline TXT_EDIT & 0.4776 & $0.0685 * *$ & 0.4937 & $0.0607 * *$ & 0.4780 & $0.0669 * *$ & 0.4580 & $0.0931 * *$ & 0.4815 & $0.1974 * *$ & & \\
\hline CONNECT & 0.3104 & $0.1142 * *$ & 0.4655 & $0.0972 * *$ & & & 0.3165 & 0.1697 & 0.3164 & $0.1560 *$ & & \\
\hline Windows_2000_Pro & & & & & & & & & & & 2.7081 & $0.2009 * *$ \\
\hline Windows_NT_Workstation_40 & & & & & & & & & & & 2.0479 & $0.2078 * *$ \\
\hline Windows_98 & & & & & & & & & & & 1.6784 & $0.2278 * *$ \\
\hline Windows_95 & & & & & & & & & & & 1.3658 & $0.1352 * *$ \\
\hline Windows_31 & & & & & & & & & & & 0.5767 & $0.0996 * *$ \\
\hline OS2_Warp_30 & & & & & & & & & & & 0.4778 & $0.1297 * *$ \\
\hline OS2 20 & & & & & & & & & & & 1.0587 & $0.1005 * *$ \\
\hline MS_DOS_622 & & & & & & & & & & & 0.3754 & 0.2780 \\
\hline MS_DOS_50 & & & & & & & & & & & 0.4580 & $0.0938 * *$ \\
\hline PC_DOS_33 & & & & & & & & & & & 0.2248 & $0.0949 *$ \\
\hline DR_DOS 60 & & & & & & & & & & & 0.3298 & $0.1039 * *$ \\
\hline $\mathrm{q}^{2}-\mathrm{DOS}_{-} \mathrm{Ou}$ & -0.1150 & $0.0452 *$ & & & -0.1068 & $0.0446 *$ & -0.0661 & 0.0825 & -0.1190 & 0.0722 & $\begin{array}{r}-0.0618 \\
-\end{array}$ & 0.0585 \\
\hline q3 & -0.1504 & $0.0420 * *$ & & & -0.1372 & $0.0423 * *$ & -0.1501 & 0.0804 & -0.1541 & $0.0723 *$ & -0.1556 & $0.0603 *$ \\
\hline q4 & -0.1646 & $0.0430 * *$ & & & -0.1633 & 0.0434 ** & -0.1449 & 0.0818 & -0.1697 & $0.0718 *$ & -0.1739 & $0.0656 * *$ \\
\hline t88 & -0.1364 & $0.0257^{* *}$ & & & -0.1335 & $0.0246 * *$ & -0.1308 & $0.0563 *$ & -0.1361 & 0.2145 & -0.0959 & 0.0723 \\
\hline t89 & -0.1385 & 0.0303 ** & & & -0.1334 & $0.0290 * *$ & -0.1246 & $0.0582 *$ & -0.1395 & 0.2305 & -0.1343 & $0.0548 *$ \\
\hline t90 & $\begin{array}{l}-0.3197 \\
-\end{array}$ & $0.0414 * *$ & & & -0.3153 & 0.0407 ** & $\begin{array}{l}-0.2587 \\
-\end{array}$ & $0.0885 * *$ & -0.3158 & 0.2099 & $\begin{array}{l}-0.1559 \\
-\end{array}$ & 0.0811 \\
\hline t91 & -0.4852 & $0.0416 * *$ & & & -0.4803 & $0.0400^{* *}$ & -0.4487 & $0.0646 * *$ & -0.4860 & $0.2421 *$ & -0.2335 & $0.1151 *$ \\
\hline 192 & -0.8564 & $0.0786^{* *}$ & & & -0.8609 & $0.0764 * *$ & -0.8153 & 0.1208 ** & -0.8610 & $0.2891 * *$ & -0.5348 & $0.1435 * *$ \\
\hline 193 & -0.9721 & $0.0879^{* *}$ & & & -0.9718 & $0.0862 * *$ & -0.9751 & 0.1413 ** & -0.9762 & $0.3023^{* *}$ & -0.6322 & $0.1475 * *$ \\
\hline t94 & -1.0685 & $0.0917^{* *}$ & & & -1.0714 & $0.0893 * *$ & -1.0891 & 0.1436 ** & -1.0715 & $0.3160 * *$ & -0.6775 & $0.1591 * *$ \\
\hline t95 & -1.0949 & 0.0997 ** & & & -1.1040 & 0.0937 ** & -1.1010 & $0.1546 * *$ & -1.1028 & $0.3222 * *$ & -0.6714 & $0.1566 * *$ \\
\hline t96 & -1.2329 & 0.1576 ** & & & -1.2489 & $0.1505^{* *}$ & -1.2700 & 0.2831 ** & -1.2412 & $0.3441 * *$ & -0.6291 & $0.1768 * *$ \\
\hline t97 & -1.3273 & $0.1683 * *$ & & & -1.2148 & 0.1425 ** & -1.2121 & $0.2581 * *$ & -1.3399 & $0.3595 * *$ & -0.9373 & $0.2619^{* *}$ \\
\hline t98 & -1.6071 & $0.1566 * *$ & & & -1.4241 & 0.1398 ** & -1.5948 & $0.2395 * *$ & $\begin{array}{l}-1.5966 \\
\end{array}$ & $0.3509 * *$ & -1.3176 & $0.2561 * *$ \\
\hline $\begin{array}{l}190 \\
\end{array}$ & $\begin{array}{l}-1.9590 \\
-\end{array}$ & 0.1457 ** & & & $\begin{array}{l}-1.7914 \\
-1.7914\end{array}$ & $0.1263 * *$ & $\begin{array}{l}-1.9415 \\
-\end{array}$ & 0.2110 ** & $\begin{array}{l}-1.9549 \\
\end{array}$ & $0.3485 * *$ & -1.6578 & $0.2284 * *$ \\
\hline too & -2.3952 & $0.1662 * *$ & & & -2.2227 & $0.1543 * *$ & -2.2988 & $0.2454 * *$ & -2.4063 & $0.3756 * *$ & -2.0568 & $0.2284 * *$ \\
\hline $\mathrm{N}$ & 340 & & 340 & & 340 & & 96 & & 96 & & 96 & \\
\hline $\mathrm{R}^{2}$ & 0.7039 & & 0.7958 & & 0.6913 & & 0.7231 & & 0.7569 & & 0.8705 & \\
\hline Adjusted $R^{2}$ & 0.6833 & & 0.7528 & & 0.6709 & & 0.6397 & & & & 0.8191 & \\
\hline $\operatorname{AAGR}(1987-2000)$ & $-16.83 \%$ & & $-17.52 \%$ & & $-15.72 \%$ & & $-16.21 \%$ & & $-16.90 \%$ & & $-14.63 \%$ & \\
\hline $\operatorname{AAGR}(1987-1993)$ & $-14.96 \%$ & & $-15.05 \%$ & & $-14.95 \%$ & & $-15.00 \%$ & & $-15.01 \%$ & & $-10.00 \%$ & \\
\hline $\operatorname{AAGR}(1993-2000)$ & $-18.40 \%$ & & $-19.68 \%$ & & $-16.36 \%$ & & $-17.23 \%$ & & $-18.48 \%$ & & $-18.41 \%$ & \\
\hline \multicolumn{13}{|c|}{ Connectivity, Platform and Filesys Variables Included } \\
\hline AAGR $(1987-2000)$ & $-18.16 \%$ & & $-18.89 \%$ & & & & $-16.70 \%$ & & $-18.24 \%$ & & & \\
\hline AAGR (1987-1993) & $-14.91 \%$ & & $-14.57 \%$ & & & & $-14.94 \%$ & & $-14.98 \%$ & & & \\
\hline AAGR (1993-2000) & $-20.85 \%$ & & $-22.57 \%$ & & & & $-18.17 \%$ & & $-20.94 \%$ & & & \\
\hline \multicolumn{13}{|c|}{ Connectivity and Platform Variables Included } \\
\hline AAGR (1987-2000) & $-17.18 \%$ & & $-17.70 \%$ & & & & $-16.53 \%$ & & $-17.26 \%$ & & & \\
\hline $\operatorname{AAGR}(1987-1993)$ & $-15.63 \%$ & & $-15.48 \%$ & & & & $-15.69 \%$ & & $-15.70 \%$ & & & \\
\hline AAGR (1993-2000) & $-18.48 \%$ & & $-19.64 \%$ & & & & $-17.24 \%$ & & $-18.57 \%$ & & & \\
\hline
\end{tabular}




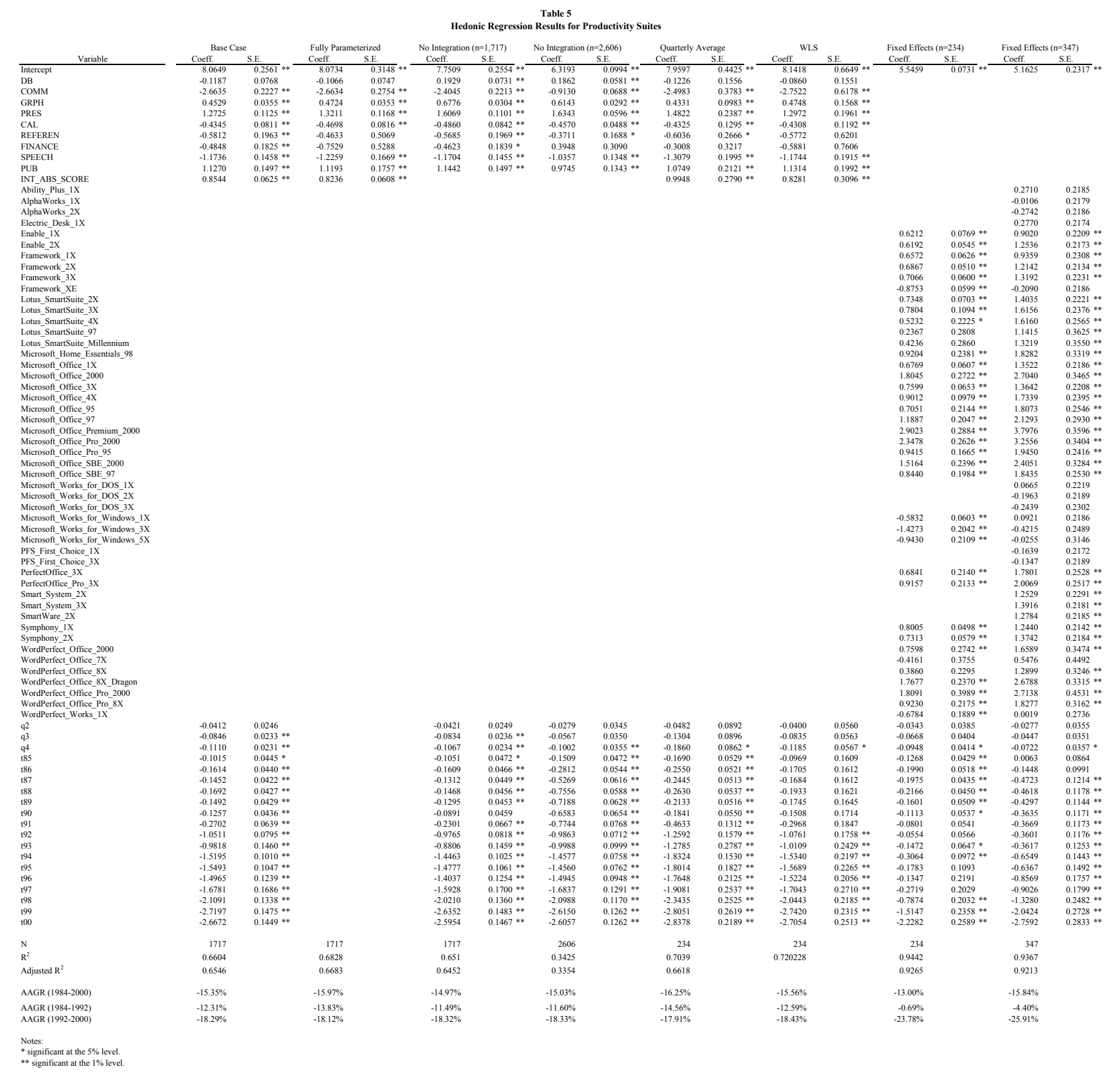


Figure 1

Average Connectivity Score of Personal Computer Operating Systems

$1987-2000$

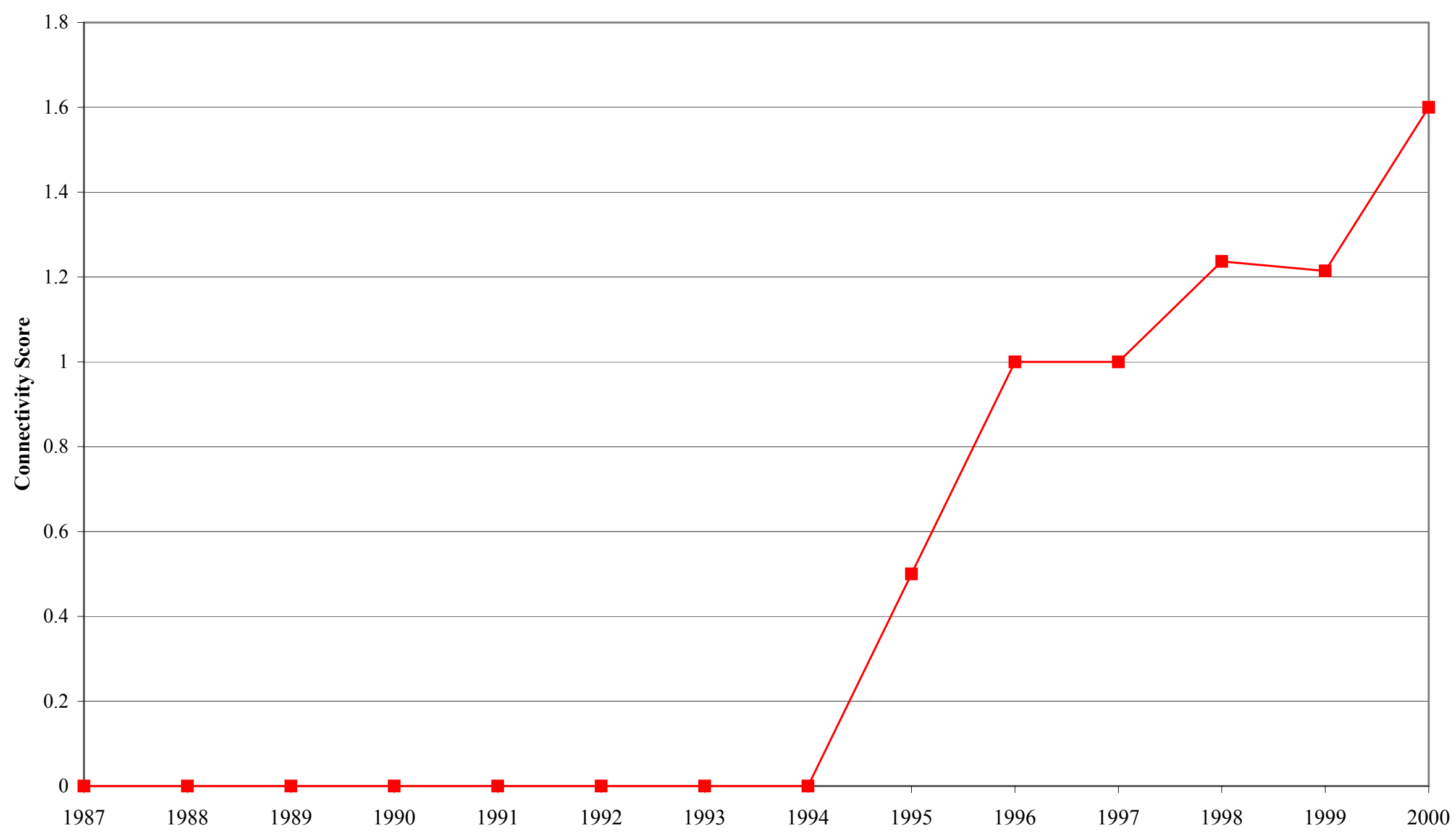


Figure 2

Average Absolute Integration Score of Productivity Suites 1984-2000

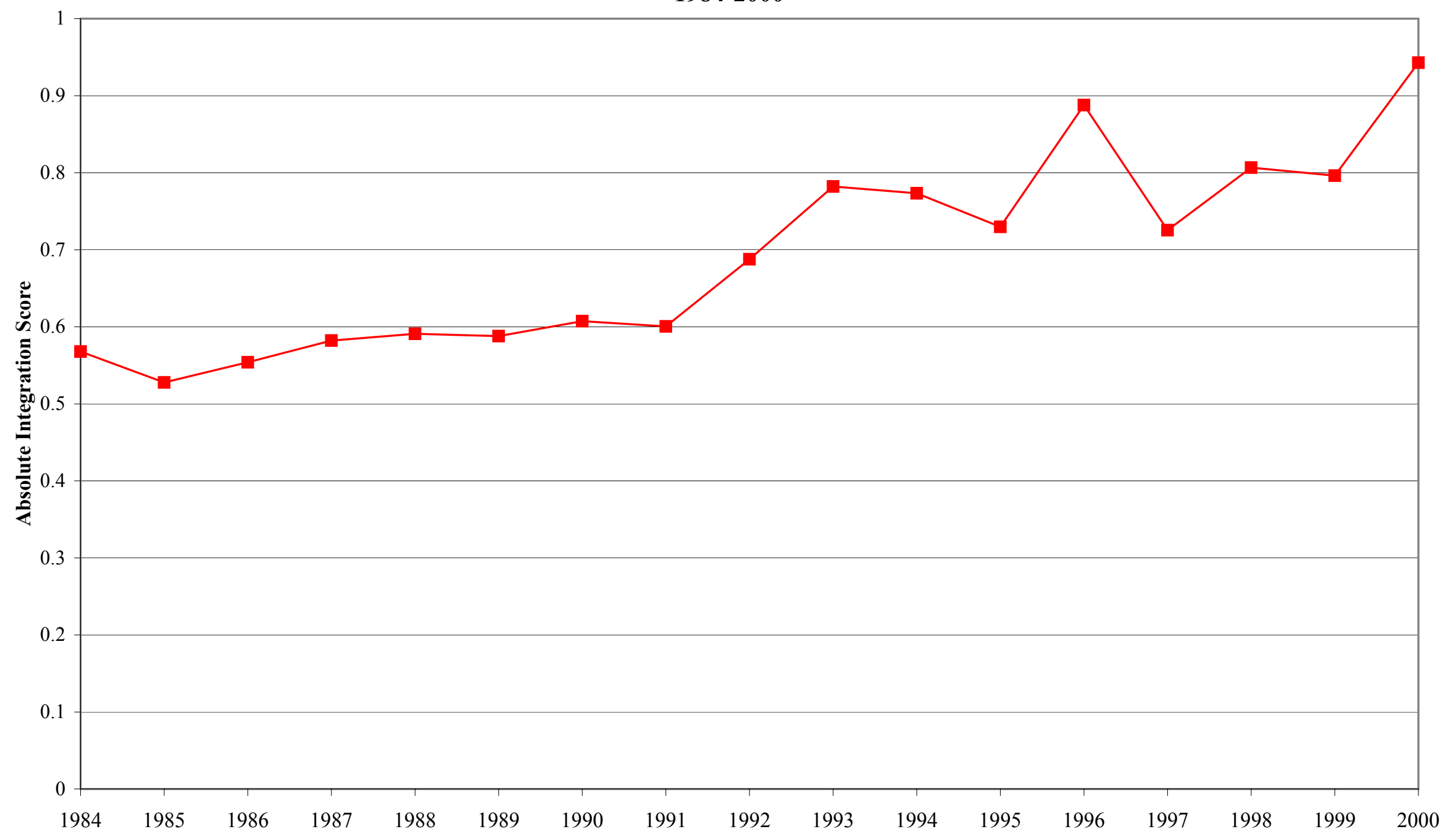


Figure 3

Hedonic, Matched-model, and Average Price Level Price Indexes

Personal Computer Operating Systems

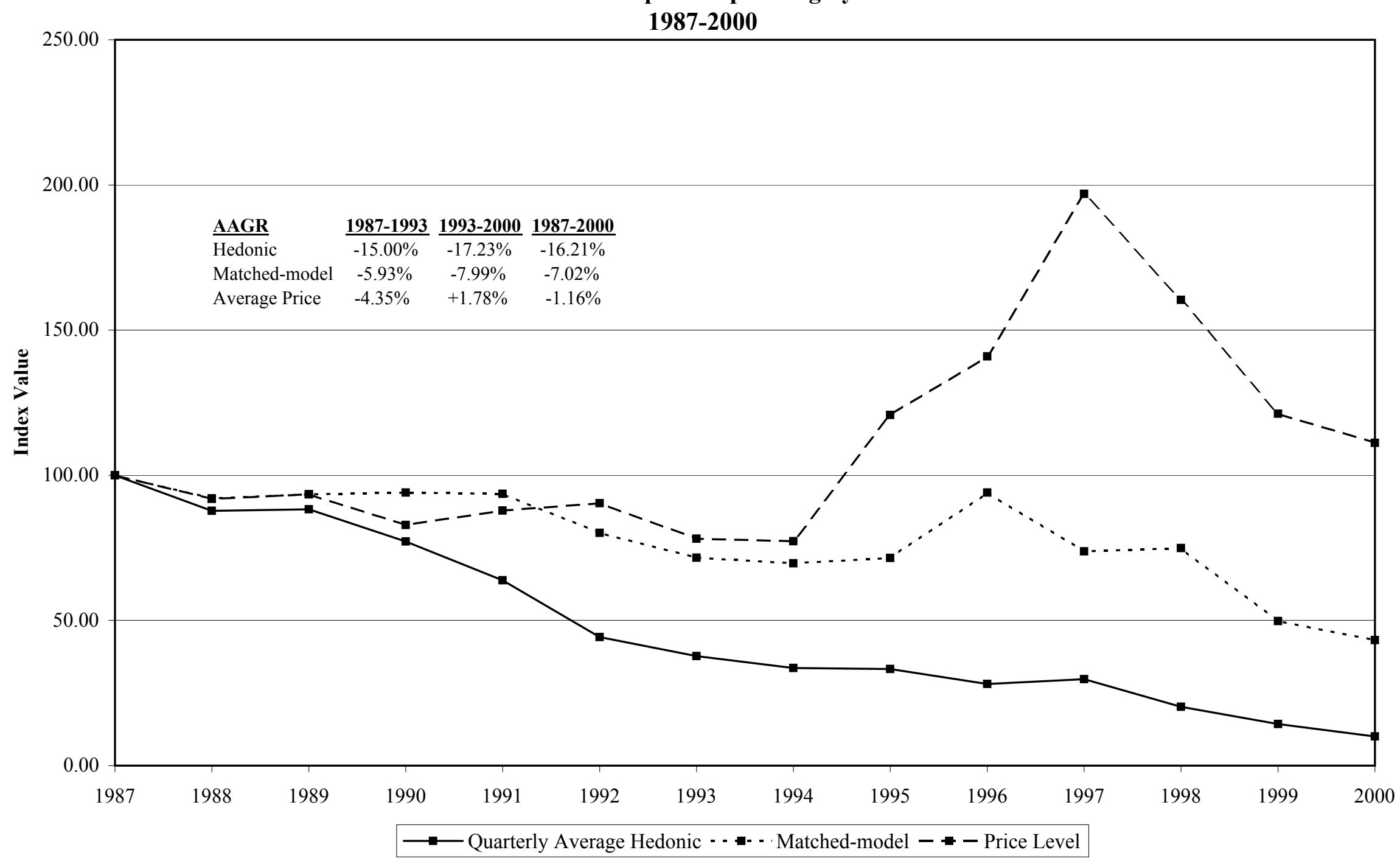


Figure 4

Hedonic, Matched-model, and Average Price Level Price Indexes

Productivity Suites

1984-2000

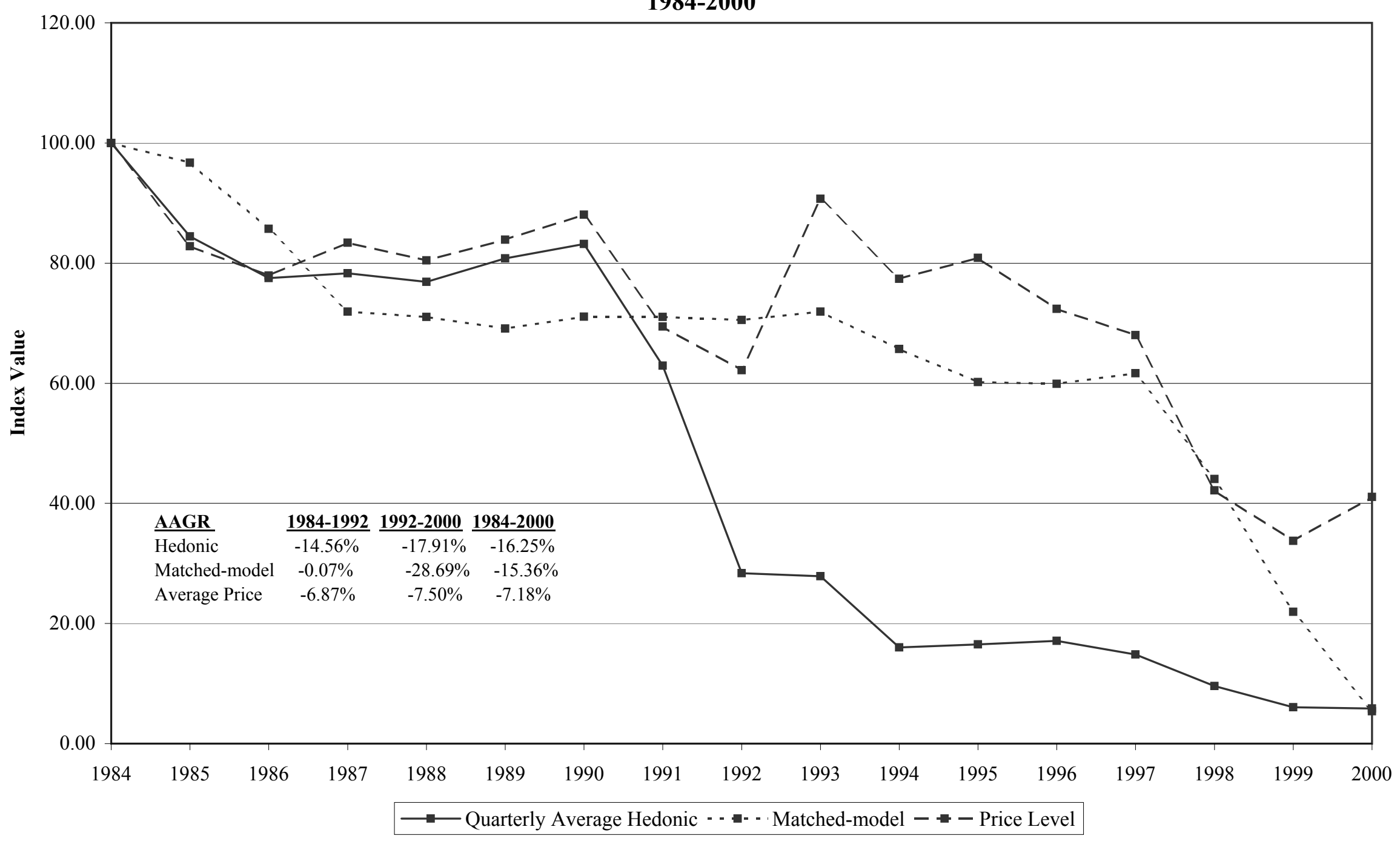


Appendix A

Price Index Values for Personal Computer Operating Systems, 1987-2000

\begin{tabular}{|c|c|c|c|c|c|}
\hline \multirow[b]{2}{*}{ Year } & \multicolumn{4}{|c|}{ Hedonics } & \multirow[b]{2}{*}{$\underline{\text { WLS }}$} \\
\hline & Base Case & Fully Parameterized * & No Compatibility & Quarterly Average & \\
\hline 1987 & 100.00 & 100.00 & 100.00 & 100.00 & 100.00 \\
\hline 1988 & 87.25 & 91.97 & 87.50 & 87.74 & 87.27 \\
\hline 1989 & 87.06 & 93.42 & 87.51 & 88.28 & 86.98 \\
\hline 1990 & 72.64 & 78.53 & 72.95 & 77.21 & 72.92 \\
\hline 1991 & 61.55 & 65.28 & 61.86 & 63.85 & 61.51 \\
\hline 1992 & 42.47 & 45.15 & 42.28 & 44.25 & 42.27 \\
\hline 1993 & 37.83 & 39.54 & 37.84 & 37.72 & 37.68 \\
\hline 1994 & 34.35 & 37.09 & 34.25 & 33.65 & 34.25 \\
\hline 1995 & 33.46 & 39.35 & 33.15 & 33.25 & 33.20 \\
\hline 1996 & 29.14 & 36.86 & 28.68 & 28.08 & 28.90 \\
\hline 1997 & 26.52 & 31.62 & 29.68 & 29.76 & 26.19 \\
\hline 1998 & 20.05 & 20.51 & 24.07 & 20.29 & 20.26 \\
\hline 1999 & 14.10 & 15.23 & 16.67 & 14.35 & 14.16 \\
\hline 2000 & 9.12 & 10.11 & 10.83 & 10.04 & 9.02 \\
\hline AAGR (1987-2000) & $-16.83 \%$ & $-17.52 \%$ & $-15.72 \%$ & $-16.21 \%$ & $-16.90 \%$ \\
\hline AAGR (1987-1993) & $-14.96 \%$ & $-15.05 \%$ & $-14.95 \%$ & $-15.00 \%$ & $-15.01 \%$ \\
\hline AAGR (1993-2000) & $-18.40 \%$ & $-19.68 \%$ & $-16.36 \%$ & $-17.23 \%$ & $-18.48 \%$ \\
\hline
\end{tabular}

\begin{tabular}{rrr}
\multicolumn{3}{c}{ Fixed Effects and Matched-models } \\
\hline Fixed Effects & Geometric * & Fisher * \\
\cline { 2 - 2 } & & \\
100.00 & 100.00 & 100.00 \\
90.85 & 92.07 & 92.07 \\
87.44 & 93.40 & 93.40 \\
85.56 & 94.00 & 93.46 \\
79.18 & 93.57 & 90.71 \\
58.58 & 80.12 & 72.38 \\
53.14 & 71.60 & 64.28 \\
50.79 & 69.65 & 62.53 \\
51.10 & 71.50 & 64.09 \\
53.31 & 94.00 & 64.08 \\
39.17 & 73.78 & 68.19 \\
26.78 & 74.88 & 66.98 \\
19.06 & 49.81 & 41.07 \\
12.79 & 43.20 & 37.49 \\
$-14.63 \%$ & $-7.02 \%$ & $-7.43 \%$ \\
$-10.00 \%$ & $-5.93 \%$ & $-7.53 \%$ \\
$-18.41 \%$ & $-7.99 \%$ & $-7.34 \%$
\end{tabular}

Price Levels

$\underline{\text { Index of Price Levels * }}$

100.00

91.82

93.40

82.86

87.85

90.34
78.18

78.18

120.78

140.97

140.97

196.89

160.40

121.20

$-1.16 \%$

$-4.35 \%$

* Annual index values are arithmetic averages of quarterly index values, rebased to equal 100 in 1987. 
Appendix B

Price Index Values for Productivity Suites, 1984-2000

\begin{tabular}{|c|c|c|c|c|c|c|}
\hline \multirow[b]{2}{*}{ Year } & \multicolumn{5}{|c|}{$\underline{\text { Hedonic }}$} & \multirow[b]{2}{*}{$\underline{\text { WLS }}$} \\
\hline & Base Case & Fully Parameterized * & No Integration $(n=1,717)$ & No Integration $(n=2,606)$ & Quarterly Average & \\
\hline 1984 & 100.00 & 100.00 & 100.00 & 100.00 & 100.00 & 100.00 \\
\hline 1985 & 90.35 & 88.93 & 90.02 & 86.00 & 84.45 & 90.76 \\
\hline 1986 & 85.09 & 84.92 & 85.14 & 75.49 & 77.49 & 84.32 \\
\hline 1987 & 86.48 & 84.11 & 87.71 & 59.04 & 78.31 & 84.50 \\
\hline 1988 & 84.44 & 83.97 & 86.34 & 46.97 & 76.88 & 82.42 \\
\hline 1989 & 86.14 & 85.94 & 87.86 & 48.74 & 80.79 & 83.99 \\
\hline 1990 & 88.19 & 88.71 & 91.48 & 51.77 & 83.19 & 86.00 \\
\hline 1991 & 76.32 & 76.38 & 79.45 & 46.10 & 62.92 & 74.32 \\
\hline 1992 & 34.95 & 34.92 & 37.66 & 37.29 & 28.39 & 34.09 \\
\hline 1993 & 37.46 & 37.29 & 41.45 & 36.83 & 27.85 & 36.39 \\
\hline 1994 & 21.88 & 21.27 & 23.54 & 23.28 & 16.00 & 21.57 \\
\hline 1995 & 21.24 & 20.70 & 22.82 & 23.32 & 16.51 & 20.83 \\
\hline 1996 & 22.39 & 22.44 & 24.57 & 22.44 & 17.12 & 21.82 \\
\hline 1997 & 18.67 & 18.27 & 20.34 & 18.57 & 14.84 & 18.19 \\
\hline 1998 & 12.13 & 12.99 & 13.25 & 12.26 & 9.60 & 12.95 \\
\hline 1999 & 6.59 & 6.95 & 7.17 & 7.32 & 6.05 & 6.44 \\
\hline 2000 & 6.94 & 7.24 & 7.46 & 7.38 & 5.86 & 6.68 \\
\hline AGR (1984-2000) & $-15.35 \%$ & $-15.97 \%$ & $-14.97 \%$ & $-15.03 \%$ & $-16.25 \%$ & $-15.56 \%$ \\
\hline AGR (1984-1992) & $-12.31 \%$ & $-13.83 \%$ & $-11.49 \%$ & $-11.60 \%$ & $-14.56 \%$ & $-12.59 \%$ \\
\hline AGR (1992-2000) & $-18.29 \%$ & $-18.12 \%$ & $-18.32 \%$ & $-18.33 \%$ & $-17.91 \%$ & $-18.43 \%$ \\
\hline
\end{tabular}

* Annual index values are arithmetic averages of quarterly index values, rebased to equal 100 in 1984. 
Appendix B (continued)

Price Index Values for Productivity Suites, 1984-2000

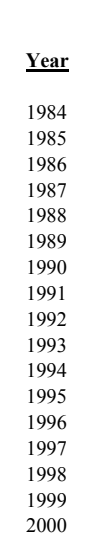

\begin{abstract}
Fixed Effects (n=234)
\end{abstract}
Fixed Effects

Year

1984
1985

1986

988

991

1992

9967

AGR (1984-2000)

AAGR (1984-1992)

$-13.00 \%$

$-23.78 \%$

$-15.84 \%$

$-4.40 \%$
$-25.91 \%$

$\begin{array}{rr}100.00 & 100.00 \\ 88.09 & 100.63 \\ 81.96 & 86.52 \\ 82.08 & 62.36 \\ 80.53 & 63.02 \\ 85.21 & 65.07 \\ 89.47 & 69.52 \\ 92.30 & 69.29 \\ 94.61 & 69.76 \\ 86.31 & 69.65 \\ 73.61 & 51.95 \\ 83.67 & 52.90 \\ 87.40 & 42.45 \\ 76.19 & 40.55 \\ 45.50 & 26.50 \\ 21.99 & 12.97 \\ 10.77 & 6.33\end{array}$

* Annual index values are arithmetic averages of quarterly index values, rebased to equal 100 in 1987.
Matched-models

\begin{tabular}{r}
\hline Geometric Unweighted $(\mathbf{n}=\mathbf{2 3 4}) *$ \\
100.00 \\
96.07 \\
92.03 \\
90.58 \\
89.28 \\
93.16 \\
97.26 \\
100.65 \\
101.30 \\
90.58 \\
88.31 \\
84.03 \\
84.77 \\
8.47 \\
63.22 \\
31.46 \\
7.72 \\
\\
\\
$-15.36 \%$ \\
$-0.07 \%$ \\
$-28.69 \%$
\end{tabular}

Geometric Unweighted ( $\mathrm{n}=347$ ) *

100.00
96.73

85.69
71.92

71.03
69.09

71.03
71.09
71.03

70.53

71.92
65.70

60.19

59.88

61.67

44.07
21.93

5.38

$-17.22 \%$

$-28.58 \%$
Fisher ( $(\mathbf{n}=234)$ *

100.00
93.04

93.04
88.80

87.42
85.99

87.19
90.98

90.98
95.72
94.88

94.88

88.78
84.53

80.46

81.96

82.59

44.62
16.45

9.02

$-14.17 \%$

$-1.66 \%$
$-25.41 \%$
Price Levels

Index of Price Levels *

100.00

82.82

77.91

83.38
80.45

88.06

88.06
69.43

62.17

62.69
77.39

77.39
80.86

72.39

68.00
42.15

42.15
33.76

41.07

$-7.18 \%$
$-6.87 \%$

$-6.87 \%$
$-7.50 \%$ 